\title{
Management of innovation projects: financial risks
}

\author{
Tatyana Burtseva ${ }^{1,2}$, Lyudmila Rudenko ${ }^{2}$, Olga Fokina $^{1}$, and Olga Pavlyutenkova ${ }^{3}$ \\ ${ }^{1}$ Vyatka State University, 610000, 36, Moskovskaya str., Kirov, Russia \\ ${ }^{2}$ Moscow Witte University, 115432,12, 2nd Kozhukhovsky passage, Moscow, Russia \\ ${ }^{3}$ Bauman Moscow State Technical University, 105005, 5/1, 2th Baumanskaya str., Moscow, Russia
}

\begin{abstract}
Management of innovative projects requires a deep assessment of various risks, and financial risks here are especially important. Management of financial risks in the field of innovative activity significantly affects the efficiency of the whole work. It is also one of the most important components of the project activity. The article describes research results of the main target segments for planning a program of financial risk management. The research is based on a cluster analysis that describes the most significant groups of risk factors. Enterprises implementing innovative projects need to pay special attention to these factors, especially when developing various measures for the formation and development of innovative activities and the management of various risks.
\end{abstract}

\section{Introduction}

The financial risk of an enterprise is the possibility of adverse financial consequences in the form of loss of income or capital if the conditions for the implementation of its financial activities are uncertain.

Traditionally, risk management in the field of innovation means a combination of practical measures to reduce the uncertainty of innovation results, increase the usefulness of implementing an innovation, and reduce the cost of achieving an innovation goal.

From the point of view of novelty, it is necessary to distinguish between products of "world novelty" (products of market novelty) and products which are "new to the company." Since 1982 in world practice there has been the following classification of new products $[1,2]$ ( according to the analysis of 700 firms and 13,000 new industrial and consumer goods) [3]:

- goods of world novelty (10\%);

- goods new to the company (20\%);

- expansion of the existing range of goods (26\%);

- updated goods $(26 \%)$;

- change of product positioning (7\%);

- cost reduction (manufacturing innovation) (11\%).

*Corresponding author: angela-1309.m@yandex.ru 
It is clear that only a small part of innovations (10\%) has a world novelty, while most of them $(70 \%)$ are an expansion of the range of existing goods or their modification.

If we analyze the success factors of new products, we can state that their share is increasing, now it is $50-60 \%$, i.e. at best, the probability of success can be as one of two. This means that a substantial part of the costs of R\&D and commercial implementation is unproductive.

We distinguish the following stages in the system of managing financial risks of the innovative activity:

1. To determine the place of financial risk management in the management system of competitiveness of an innovative organization.

2. To find and identify possible financial risks.

3. To analyze financial risks. To choose risk management methods.

4. To response to a risk event.

5. To create an organizational and managerial mechanism in order to monitor and control financial risks in the innovative activity of enterprises.

\section{Methods}

Identification of the main target segments for program planning of financial risk management is an important step in the financial risk management system.

It is necessary to conduct a cluster analysis based on marketing research data. This multidimensional statistical analysis collects data containing information about a sample of objects and then organizes these objects into relatively homogeneous groups $[3,4,5]$. In general, cluster analysis is aimed to develop a typology or classification, to study useful conceptual schemes for grouping objects, to state hypotheses based on data research, and to test hypotheses or research in order to determine whether types (groups) identified in one way or another are actually present in the available data. In our case, cluster analysis is necessary to determine the number of main segments and to describe their demographic and psychographic characteristics.

Regardless of the subject of study, the cluster analysis involves the following steps:

1. Sampling for clustering. It makes sense to cluster only quantitative data.

2. Determination of the set of variables by which the objects in the sample will be evaluated.

3. Calculation of the values of similarity (or difference) between objects.

4. Application of the cluster analysis method in order to create groups of similar objects.

5. Validation of cluster decision results.

\section{Results}

Results of the cluster analysis of research data allow to analyze the structure of the main clusters in terms of the level of understanding the importance of main financial risks that influence the effectiveness of innovation.

Staged cluster analysis results are:

1. Finding and identification of possible financial risks (Table 1). 
Table 1. Key variables for describing target segment profiles

\begin{tabular}{|c|l|}
\hline Code & \multicolumn{1}{c|}{ List of key financial risks } \\
\hline$X_{1}$ & Risk of decreasing financial stability and equilibrium financial development \\
\hline$X_{2}$ & Insolvency risk (unbalanced liquidity) \\
\hline$X_{3}$ & Investment risk as a possibility of losses in the process of investing \\
\hline$X_{4}$ & Inflation risk (depreciation of the real cost of capital) \\
\hline$X_{5}$ & Interest rate risk (unexpected change of interest rate) \\
\hline$X_{6}$ & Currency risk \\
\hline$X_{7}$ & Deposit risk (non-repayment of deposit certificates) \\
\hline$X_{8}$ & Credit risk when providing a commodity loan to customers \\
\hline$X_{9}$ & Tax risk (introduction of new taxes and fees) \\
\hline$X_{10}$ & Structural risk (inefficient financing of current costs of the enterprise) \\
\hline$X_{11}$ & $\begin{array}{l}\text { Criminogenic risk (declaration of fictitious bankruptcy to the partners of the } \\
\text { enterprise, forgery of documents, etc.) }\end{array}$ \\
\hline$X_{12}$ & Risk of untimed cash operations \\
\hline$X_{13}$ & Emission risk \\
\hline$X_{14}$ & Information risk (lack of market information) \\
\hline
\end{tabular}

2. Determining the number of clusters. For this, we made a graph of the ratio of total dispersion within groups to intergroup dispersion (a dendrogram), which shows the corresponding number of clusters. An increase in this number is impractical, and its decrease may lead to the unification of dissimilar objects. The dendrogram (Figure 1) shows that all respondents are divided into 3 clusters.

3 . We evaluated and profiled clusters according to the data presented in Table 2. Clusters are described in terms of variables that were used for clustering (Table 1) and in terms that were not used for clustering: demographic and psychographic factors, characteristics of experts [6].

Interpretation of the results of cluster analysis allows to draw the following conclusions:

- the resulting clusters differ little in size. The third cluster stands out as it covers $38.0 \%$ of the total;

- the first cluster includes experts who highly appreciate such financial risks as X1 (risk of decreasing financial stability and equilibrium financial development), X2 (risk of insolvency or unbalanced liquidity), X3 (investment risk as the possibility of losses in the process of investment activities), X10 (structural risk, inefficient financing of the current costs of the enterprise), i.e. these respondents more seriously assess the risks associated with investment activities.

- the second cluster includes respondents who have a relatively high rating of an indicator X3 (investment risk as an opportunity to lose in the process of investing). Experts fairly neutrally assess such financial risks as X5 (interest rate risk (unexpected change of interest rate), X7 (deposit risk, non-repayment of deposit certificates), X9 (tax risk, introduction of new taxes and fees), X13 (emission risk);

- the third cluster, the largest one, includes experts who highly assess X2 (risk of insolvency, unbalanced liquidity), X3 (investment risk as a possibility of losses in the process of carrying out investment activities), X10 (structural risk or ineffective financing of current costs of the enterprise). In this cluster, the remaining variables are neutral.

According to the analysis, the resulting clusters do not differ a lot from each other. It means that experts single out the same risks for the innovation sector as the most significant risks. The variable X3 (investment risk as the possibility of losses in the process of carrying out investment activities) is significant for all categories of experts. Therefore, the company should develop programs and pursue a more competent policy to manage this risk. 
The results of the factor analysis of this research allow to point out the main factors that determine the effectiveness of financial risk management in the innovation sphere. Studies have shown that it is advisable to distinguish three main factors, three main areas of work with financial risks (Figure 2).

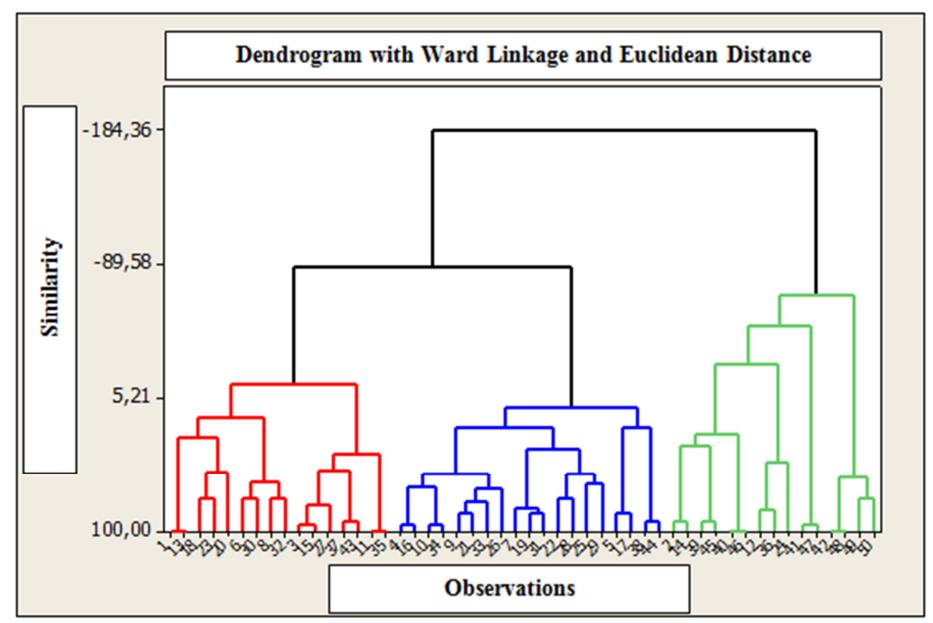

Fig.1. Dendrogram for determining the number of clusters

Table 2. Results of hierarchical cluster analysis of research data

\begin{tabular}{|c|c|c|c|c|c|c|c|c|c|c|c|c|c|c|}
\hline \multicolumn{3}{|c|}{ Cluster } & \multicolumn{8}{|c|}{ Number of objects } & \multicolumn{4}{|c|}{$\%$} \\
\hline \multicolumn{3}{|c|}{1} & \multicolumn{8}{|c|}{16} & \multicolumn{4}{|c|}{32.0} \\
\hline \multicolumn{3}{|c|}{2} & \multicolumn{8}{|c|}{15} & \multicolumn{4}{|c|}{30.0} \\
\hline \multicolumn{3}{|c|}{3} & \multicolumn{8}{|c|}{19} & \multicolumn{4}{|c|}{38.0} \\
\hline \multicolumn{15}{|c|}{ Cluster listing } \\
\hline Objects & \multicolumn{2}{|c|}{ Cluster } & \multicolumn{2}{|c|}{ Objects } & \multicolumn{2}{|c|}{ Cluster } & \multicolumn{2}{|c|}{ Objects } & \multicolumn{2}{|c|}{ Cluster } & \multicolumn{2}{|c|}{ Objects } & \multicolumn{2}{|c|}{ Cluster } \\
\hline 1 & \multicolumn{2}{|c|}{1} & \multicolumn{2}{|c|}{14} & \multicolumn{2}{|c|}{3} & \multicolumn{2}{|c|}{27} & \multicolumn{2}{|c|}{1} & \multicolumn{2}{|c|}{40} & \multicolumn{2}{|c|}{3} \\
\hline 2 & & 3 & 1 & & & 1 & 2 & & & & & 11 & & 3 \\
\hline 3 & & 1 & 1 & & & 2 & 2 & & & & & 2 & & 3 \\
\hline 4 & & 2 & 1 & & & 2 & 3 & & & 1 & & 3 & & 1 \\
\hline 5 & & 2 & 1 & & & 1 & 3 & & & 2 & & 4 & & 2 \\
\hline 6 & & 1 & 1 & & & 2 & 3 & & & 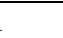 & & 15 & & 3 \\
\hline 7 & & 2 & 2 & & & 1 & 3 & & & & & 16 & & 3 \\
\hline 8 & & 1 & 2 & & & 2 & 3 & & & & & 77 & & 3 \\
\hline 9 & & 2 & 2 & & & 2 & 3 & & & & & 8 & & 3 \\
\hline 10 & & 2 & 2 & & & 1 & 3 & & & & & 19 & & 3 \\
\hline 11 & & 1 & 2 & & & 3 & 3 & & & & & 0 & & 3 \\
\hline 12 & & 3 & 2 & & & 2 & 3 & & & & & - & & - \\
\hline 13 & & 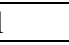 & 2 & & & 2 & 3 & & & & & - & & 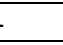 \\
\hline & & & & & & Cluste & $r$ avera & & & & & & & \\
\hline & $\mathrm{x}_{1}$ & $\mathrm{x}_{2}$ & $\mathrm{x}_{3}$ & $\mathrm{x}_{4}$ & $\mathrm{x}_{5}$ & $\mathrm{x}_{6}$ & $\mathrm{x}_{7}$ & $\mathrm{x}_{8}$ & $\mathrm{x}_{9}$ & $\mathrm{x}_{10}$ & $\mathrm{x}_{11}$ & $\mathrm{x}_{12}$ & $\mathrm{x}_{13}$ & $\mathrm{x}_{14}$ \\
\hline Cluster 1 & 8.06 & 9.43 & 8.31 & 8.0 & 6.81 & 6.31 & 5.75 & 6.12 & 5.18 & 8.50 & 6.62 & 4.93 & 5.31 & 6.25 \\
\hline Cluster 2 & 5.60 & 5.46 & 7.80 & 4.93 & 3.80 & 4.80 & 2.80 & 5.33 & 3.20 & 5.73 & 6.00 & 4.73 & 2.93 & 5.33 \\
\hline Cluster 3 & 5.94 & \begin{tabular}{|l|l|}
6.21 \\
\end{tabular} & 8.36 & 8.42 & 7.52 & \begin{tabular}{|l|l|}
4.73 \\
\end{tabular} & 3.84 & 5.52 & \begin{tabular}{|l|l|}
5.94 \\
\end{tabular} & 7.15 & \begin{tabular}{|l|l}
4.47 \\
\end{tabular} & 4.15 & 5.11 & 5.47 \\
\hline Centroid & 6.52 & 7.02 & 8.12 & 7.24 & 6.18 & 5.26 & 4.14 & 5.66 & 4.88 & 7.16 & 5.62 & 4.58 & 4.52 & 5.68 \\
\hline & & & & & & luste & centr & & & & & & & \\
\hline & 1 & & & & 000 & & & & 2456 & & & & 50622 & \\
\hline & 2 & & & & 2456 & & & & 000 & & & & 3917 & \\
\hline & 3 & & & & 0622 & & & & 3917 & & & & 000 & \\
\hline
\end{tabular}




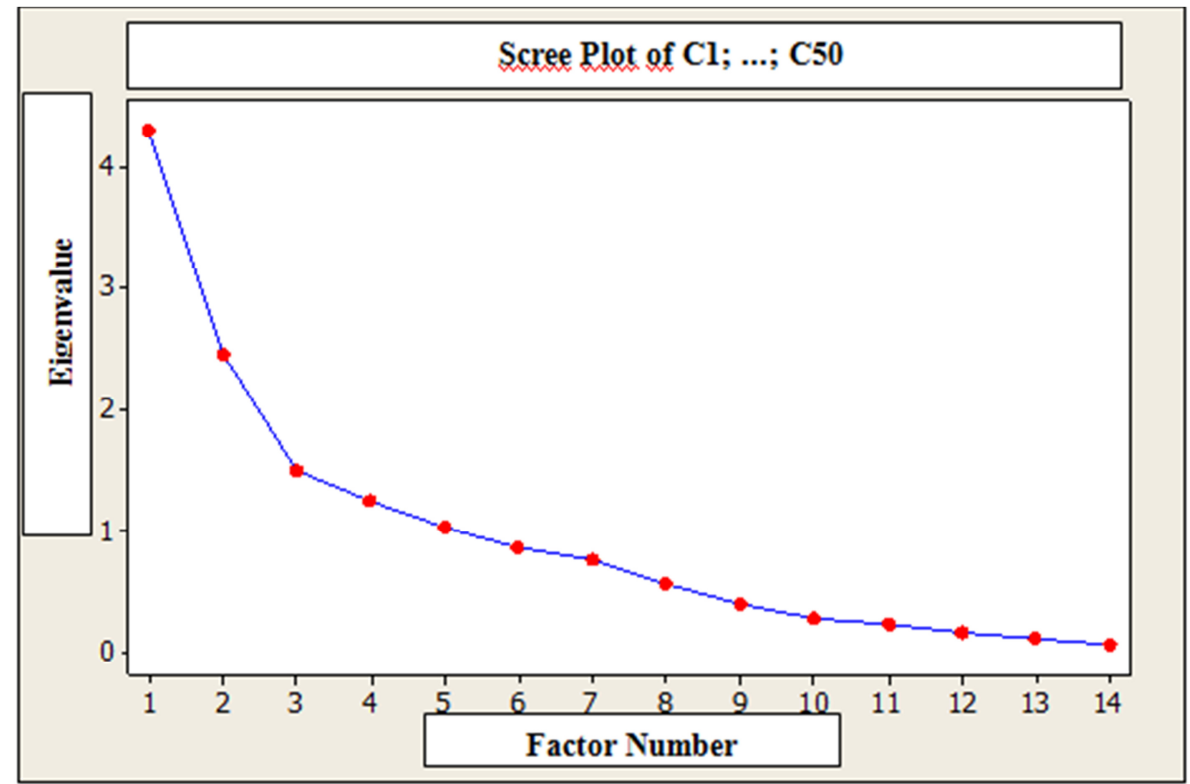

Fig.2.Graph for determining the number of factors

Factor analysis is often used to reduce the number of variables while storing as much information as possible. In the field of marketing research, the two most frequently used factorial analytical procedures are the analysis of the main components and the analysis of common factors. With a decrease in the number of variables, factor analysis tries to make the remaining variables meaningful and easy to work with, i.e. several variables can partially measure the same characteristic (factor) [7].

According to the factor analysis, we have singled out three factors that are most important in managing financial risks (Table 3):

1. Risks associated with investment activities.

2. The risk of reduced financial stability and equilibrium financial development.

3. Depreciation of the real value of capital.

Increasing attention to the identified factors can significantly help in the formation and development of the financial risk management system.

Results of the analysis and interpretation of the assessment data of the main significant factors in the financial risk management system are presented in Figure 3. 
Table 3. Factor analysis of results of assessing the significance of financial risks

\begin{tabular}{|c|c|c|c|c|c|c|c|c|c|c|c|c|c|c|}
\hline \multicolumn{15}{|c|}{$\begin{array}{l}\text { Preliminary generality estimates; eigenvalues of the correlation matrix: } \\
\text { amount }=18\end{array}$} \\
\hline & $\mathrm{x}_{1}$ & $\mathrm{x}_{2}$ & $\mathrm{x}_{3}$ & $\mathrm{x}_{4}$ & $\mathrm{x}_{5}$ & $\mathrm{x}_{6}$ & $\mathrm{x}_{7}$ & $\mathrm{x}_{8}$ & $\mathrm{x}_{9}$ & $\mathrm{x}_{10}$ & $\mathrm{x}_{11}$ & $\mathrm{x}_{12}$ & $\mathrm{x}_{13}$ & $\mathrm{x}_{14}$ \\
\hline igenvalues. & 4.29 & 2.45 & 1.50 & 1.25 & 1.03 & 0.86 & 0.77 & 0.56 & 0.39 & \begin{tabular}{|l|}
0.27 \\
\end{tabular} & 0.22 & \begin{tabular}{|l|l|}
2 & 0.16 \\
\end{tabular} & 0.12 & 0.06 \\
\hline Share, $\%$ & 30.7 & 17.5 & 10.8 & 8.9 & 7.4 & 6.2 & \begin{tabular}{l|l|}
5.5 \\
\end{tabular} & 4.0 & 2.9 & 2.0 & 1.6 & 1.2 & 0.90 & 0.05 \\
\hline \multicolumn{15}{|c|}{ Factor model } \\
\hline & & & \multicolumn{3}{|c|}{ Factor 1} & \multicolumn{3}{|c|}{ Factor 2} & \multicolumn{3}{|c|}{ Factor 3} & \multicolumn{3}{|c|}{ Generality } \\
\hline \multicolumn{3}{|c|}{$X_{1}$} & \multicolumn{3}{|c|}{0.236} & \multicolumn{3}{|c|}{0.778} & \multicolumn{3}{|c|}{0.130} & \multicolumn{3}{|c|}{0.677} \\
\hline \multicolumn{3}{|c|}{$\mathrm{X}_{2}$} & \multicolumn{3}{|c|}{0.472} & \multicolumn{3}{|c|}{0.692} & \multicolumn{3}{|c|}{0.214} & \multicolumn{3}{|c|}{0.746} \\
\hline \multicolumn{3}{|c|}{$\mathrm{X}_{3}$} & \multicolumn{3}{|c|}{0.622} & \multicolumn{3}{|c|}{0.127} & \multicolumn{3}{|c|}{0.213} & \multicolumn{3}{|c|}{0.448} \\
\hline \multicolumn{3}{|c|}{$\mathrm{X}_{4}$} & \multicolumn{3}{|c|}{0.611} & \multicolumn{3}{|c|}{0.128} & \multicolumn{3}{|c|}{0.556} & \multicolumn{3}{|c|}{0.699} \\
\hline & $\mathrm{X}_{5}$ & & & 0.705 & & & 0.184 & & & 0.475 & & & 0.757 & \\
\hline & $\mathrm{X}_{6}$ & & & 0.508 & & & 0.396 & & & 0.092 & & & 0.424 & \\
\hline & $\mathrm{X}_{7}$ & & & 0.752 & & & 0.229 & & & 0.395 & & & 0.774 & \\
\hline & $X_{8}$ & & & 0.243 & & & 0.325 & & & 0.280 & & & 0.243 & \\
\hline & $\mathrm{X}_{9}$ & & & 0.587 & & & 0.145 & & & 0.426 & & & 0.547 & \\
\hline & $\mathrm{X}_{10}$ & & & 0.771 & & & 0.138 & & & 0.262 & & & 0.682 & \\
\hline & $X_{11}$ & & & 0.3 .91 & & & 0.347 & & & 0.512 & & & 0.536 & \\
\hline & $X_{12}$ & & & 0.261 & & & 0.650 & & & 0.085 & & & 0.498 & \\
\hline & $X_{13}$ & & & 0.705 & & & 0.076 & & & 0.173 & & & 0.532 & \\
\hline & $X_{14}$ & & & 0.473 & & & 0.633 & & & 0.268 & & & 0.697 & \\
\hline & & & & Varic & ance $\mathrm{e}$ & explain & ed by & each fo & ictor & & & & & \\
\hline & $\mathrm{Fac}$ & tor 1 & & & & & actor 2 & & & & & Factor & & \\
\hline & & 298 & & & & & 2.454 & & & & & 1.507 & & \\
\hline & & 0.7 & & & & & 17.5 & & & & & 10.8 & & \\
\hline & & Factor & & Factor 2 & & Gactor 3 & & & & actor 1 & & ictor 2 & Factc & or 3 \\
\hline $\mathrm{X}_{1}$ & & 0.055 & & 0.317 & & 0.086 & & $\mathrm{X}_{8}$ & & 0.057 & & 0.132 & -0.1 & 186 \\
\hline $\mathrm{X}_{2}$ & & 0.110 & & 0.282 & & 0.142 & & $\mathrm{X}_{9}$ & & 0.137 & & .059 & -0.2 & 282 \\
\hline$X_{3}$ & & 0.145 & & -0.052 & & 0.141 & & $X_{10}$ & & 0.179 & & .056 & 0.17 & 74 \\
\hline $\mathrm{X}_{4}$ & & 0.142 & & 0.052 & & -0.369 & & $X_{11}$ & & 0.091 & & 0.141 & 0.3 & 40 \\
\hline $\mathrm{X}_{5}$ & & 0.164 & & 0.075 & & -0.315 & & $X_{12}$ & & 0.061 & & 0.265 & -0.0 & 056 \\
\hline $\mathrm{X}_{6}$ & & 0.118 & & -0.161 & & 0.061 & & $X_{13}$ & & 0.164 & & .031 & -0.1 & 115 \\
\hline $\mathrm{X}_{7}$ & & 0.175 & & 0.093 & & 0.262 & & $X_{14}$ & & 0.110 & & 0.258 & 0.17 & 78 \\
\hline
\end{tabular}


The main stages of identifying significant factors which influence the effectiveness of financial risk management in the innovation sphere

$\mathrm{X}_{1}$ - Risk of decreasing financial stability and equilibrium financial development

$\mathrm{X}_{2}$ - Risk of insolvency (unbalanced liquidity)

$\mathrm{X}_{3}$ - Investment risk as a possibility of losses in the process of investing

$\mathrm{X}_{4}$ - Inflation risk (depreciation of the real value of capital)

$\mathrm{X}_{5}$ - Interest rate risk (unexpected change of interest rate)

$\mathrm{X}_{6}$ - Currency risk

$\mathrm{X}_{7}$ - Deposit risk (non-repayment of deposit certificates)

$\mathrm{X}_{8}$ - Credit risk when providing a commodity loan to customers

$\mathrm{X}_{9}$ - Tax risk (introduction of new taxes and fees)

$\mathrm{X}_{10}$ - Structural risk (inefficient financing of current costs of the enterprise)

$\mathrm{X}_{11}$ - Criminogenic risk (declaration of fictitious bankruptcy to the partners of the enterprise, forgery of documents, etc.)

$\mathrm{X}_{12}$ - Risk of untimed cash operations

$\mathrm{X}_{13}$ - Emission risk

$\mathrm{X}_{\mathrm{I}^{1}}$ - Information risk (lack of market information)

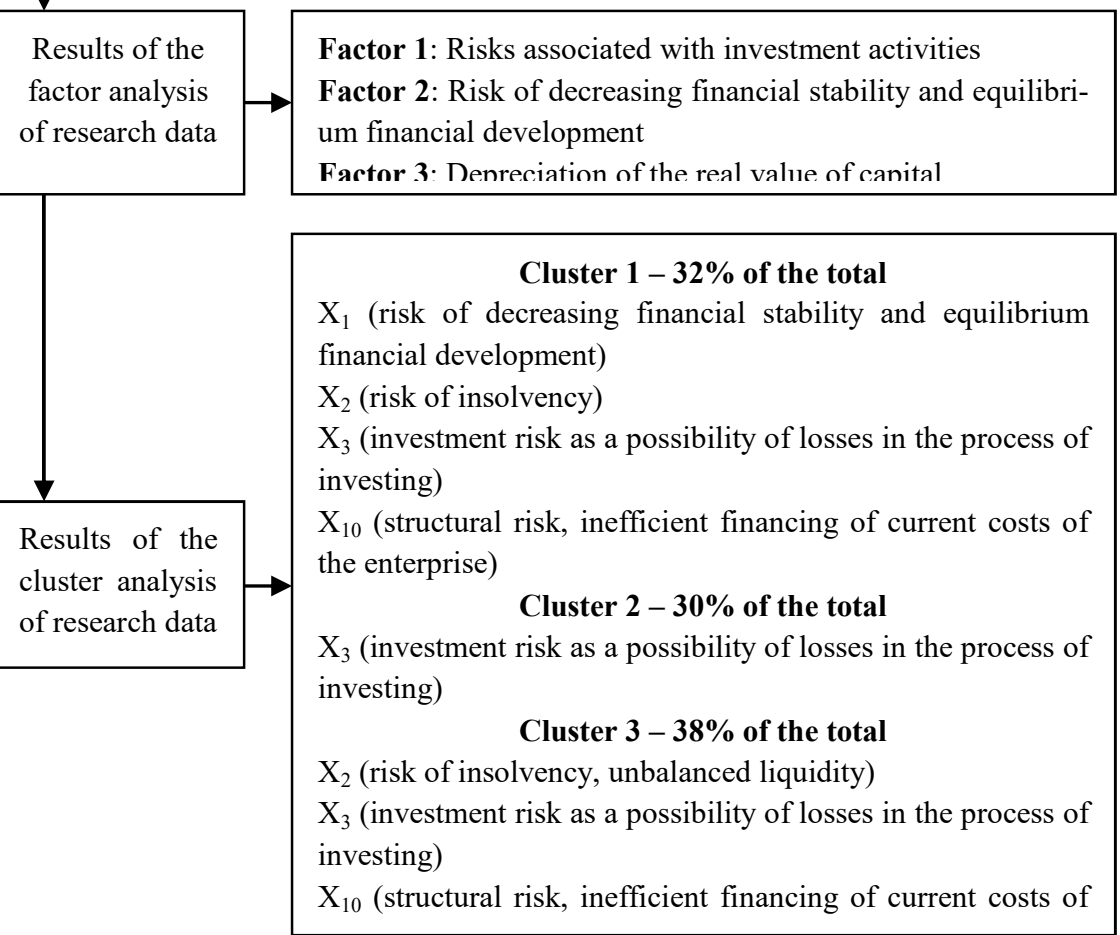

Fig.3. Assessment results of the main significant factors in the financial risk management system

\section{Discussion}

Research in the field of innovation has shown that there are several basic rules for the success of innovation [8]. A perfect product is a differentiated unique product, it gives addi- 
tional benefits to customers. Strong marketing orientation is a focus on market and customer development. The global concept of goods is when the design and development of goods focused on the world market from the very beginning. Intensive initial analysis is when there are human and financial resources for an in-depth feasibility study even before the start of development. The exact formulation of the concept is a list of specific tasks, the choice of the target market, a set of properties and product positioning. A structured development plan is the transition from intended positioning to an operational marketing plan in terms of price, sales and communications. Cross-functional coordination - a new product the business of the whole company (R\&D - Production - Marketing). Leadership support: instead of direct intervention, there is a special innovation support structure, resources and a correct vision of the process. Using synergies means to realize strong points using technological or commercial synergies. The attractiveness of markets: a factor contributes to success, but cannot compensate for the weaknesses of other factors. Preliminary selection: success and failure can be foreseen, preliminary assessment facilitates the decision to accept / reject. Monitoring the progress of development: a factor in monitoring the implementation of the development plan is very important for success. Access to resources: for the success of the project it is necessary to have human and financial resources, which should be considered as investments, not costs. The role of the time factor: a quick entry into the market is a source of competitive advantage, but this goal should be achieved considering the quality of products. Multistage procedure: it is useful to conduct the development step by step. As you can see, a significant part of them is associated with financial management, financial risk management

\section{Conclusion}

Thus, it is possible to single out the main areas of financial risk management, which are the most important for the formation of the effective activity of the enterprise in the field of innovation. The enterprise should pay special attention to these factors in the development of various measures for the formation and development of innovative activities and the management of various risks.

\section{References}

1. R. Karaffa, SCM30 (2012), https://blog.kinaxis.com/2012/03/scm30-what-can-welearn-from-supply-chain-management-mistakes/

2. M. Herman, S. Rivera, S. Mills, M. Kim, The Field Guide to Data Science. Booz Allen Hamilton (2013)

3. H. Driver, A. Kroeber, University of California Publications in American Archaeology and Ethnology, 211-256 (1932)

4. R. Tryon, Cluster Analysis: Correlation Profile and Orthometric (factor) Analysis for the Isolation of Unities in Mind and Personality. Edwards Brothers (1939)

5. R. Cattell, The description of personality: Basic traits resolved into clusters. Journal of Abnormal and Social Psychology, 38 (4), 476-506 (1943), doi:10.1037/h0054116

6. T.A. Burtseva, N.K. Savelyeva, Economics and Entrepreneurship, 11(4), 191-194 (2014)

7. L.N. Nikolova, D. G. Rodionov, M.A. Bahauovna, International Journal of Economics and Financial, 6(2), 246-252 (2016)

8. J.J. Lamben. Strategic marketing. European perspective. St. Petersburg: Science (1996) 